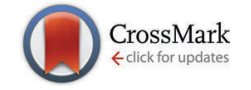

Cite this: Chem. Commun., 2015, 51, 13619

Received 15th June 2015, Accepted 22nd July 2015

DOI: $10.1039 / \mathrm{c5cc04947d}$

www.rsc.org/chemcomm

\section{First-principles evaluation of multi-valent cation insertion into orthorhombic $\mathrm{V}_{2} \mathrm{O}_{5} \dagger$}

\author{
Gopalakrishnan Sai Gautam, ${ }^{a}$ Pieremanuele Canepa, ${ }^{a}$ Rahul Malik, ${ }^{a}$ Miao Liu, \\ Kristin Persson ${ }^{\mathrm{b}}$ and Gerbrand Ceder ${ }^{\star c d}$
}

A systematic first-principles evaluation of the insertion behavior of multi-valent cations in orthorhombic $\mathrm{V}_{2} \mathrm{O}_{5}$ is performed. Layer spacing, voltage, phase stability, and ion mobility are computed for $\mathrm{Li}^{+}, \mathrm{Mg}^{2+}, \mathrm{Zn}^{2+}, \mathrm{Ca}^{2+}$, and $\mathrm{Al}^{3+}$ intercalation in the $\alpha$ and $\delta$ polymorphs.

A promising and realistic strategy to improve the energy density beyond the capability of current Li-ion battery technology is to transition to a battery architecture based on shuttling multivalent (MV) ions (e.g. $\mathrm{Mg}^{2+}$ or $\mathrm{Ca}^{2+}$ ) between an intercalation cathode host and MV metal anode. ${ }^{1,2}$ Specifically, improvement in the volumetric energy density arises from the combination of using a multi-valent metal as the anode as opposed to an insertion structure (e.g. $3833 \mathrm{mAh} \mathrm{cm}^{-3}$ volumetric capacity for $\mathrm{Mg}$ metal compared to $800 \mathrm{mAh} \mathrm{cm}^{-3}$ for graphite), and storing more charge per ion in the cathode..$^{3,4}$

One of the major bottlenecks preventing the development of MV battery technology, however, is the poor electrochemical performance of potential MV cathode materials, thought to originate predominantly from poor MV ion mobility in the intercalation host structure. ${ }^{4-6}$ Moreover, the simultaneous challenge of developing functioning MV anodes and electrolytes compatible with candidate cathode materials has limited the ability to experimentally isolate and evaluate cathode electrochemical performance, ${ }^{7}$ and as such there is a general dearth of reliable data on MV ion intercalation in the literature to date to guide the ongoing search for new MV cathode materials with improved performance.

Nevertheless, reversible electrochemical $\mathrm{Mg}^{2+}$ intercalation has been successfully demonstrated in a handful of cathode hosts,

\footnotetext{
${ }^{a}$ Department of Materials Science and Engineering, Massachusetts Institute of Technology, Cambridge, MA 02139, USA

${ }^{b}$ Environmental Energy Technologies Division, Lawrence Berkeley National Laboratory, CA 94720, USA

'Materials Science Division, Lawrence Berkeley National Laboratory, CA 94720, USA. E-mail: gceder@lbl.gov,gceder@berkeley.edu

${ }^{d}$ Department of Materials Science and Engineering, University of California Berkeley, CA 94720, USA

$\dagger$ Electronic supplementary information (ESI) available: Details on the methods used in this work provided. See DOI: 10.1039/c5cc04947d
}

namely Chevrel $\mathrm{Mo}_{6} \mathrm{~S}_{8}\left(\sim 135 \mathrm{mAh} \mathrm{g}^{-1}\right.$ capacity at $\sim 1.0-1.3 \mathrm{~V} v s . \mathrm{Mg}$ metal $),{ }^{2}$ as well as layered $\mathrm{V}_{2} \mathrm{O}_{5}\left(\sim 150 \mathrm{mAh} \mathrm{g}^{-1} \text { at } \sim 2.3-2.6 \mathrm{~V}\right)^{5,6}$ and $\mathrm{MoO}_{3}\left(\sim 220 \mathrm{mAh} \mathrm{g}^{-1}\right.$ at $\left.\sim 1.7-2.8 \mathrm{~V}\right){ }^{5}$ The orthorhombic $\mathrm{V}_{2} \mathrm{O}_{5}$ structure is especially interesting because it has also demonstrated the ability to reversibly intercalate $\mathrm{Ca}^{2+}$ and $\mathrm{Y}^{3+}$ in addition to $\mathrm{Mg}^{2+}$ ions. ${ }^{6}$ First-principles calculations (described in more detail in the $\mathrm{ESI} \dagger$ ) have proven to be an accurate and effective method to systematically assess the electrochemical properties of Li-ion batteries, ${ }^{8-10}$ and have also been used to study the process of ion intercalation in layered materials, such as graphite ${ }^{11}$ and $\mathrm{V}_{2} \mathrm{O}_{5} \cdot{ }^{12-15}$ In this work, we have performed a systematic first principles study of MV ion intercalation in the orthorhombic $\alpha-$ and $\delta-\mathrm{V}_{2} \mathrm{O}_{5}$ polymorphs by evaluating the structural change, voltage, thermodynamic stability, and intercalant mobility for $\mathrm{Li}^{+}, \mathrm{Mg}^{2+}, \mathrm{Zn}^{2+}, \mathrm{Ca}^{2+}$, and $\mathrm{Al}^{3+}$ insertion and comparing to data in the literature when available.

The crystal structure and intercalation sites of the $\alpha$ - and $\delta-\mathrm{V}_{2} \mathrm{O}_{5}$ polymorphs ${ }^{16-19}$ are shown in Fig. 1. Perpendicular to
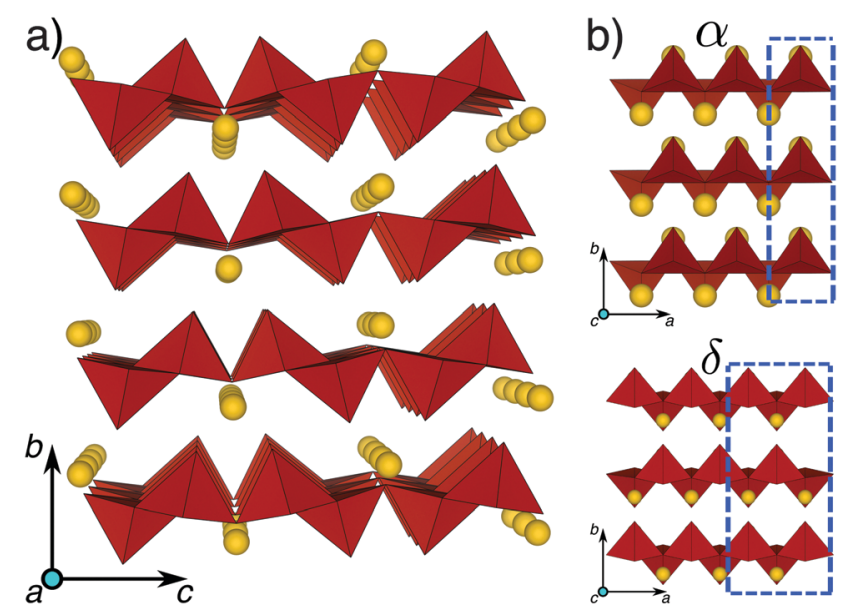

Fig. 1 (a) The $\mathrm{V}_{2} \mathrm{O}_{5}$ structure of both the $\alpha$ and $\delta$ polymorphs on the $b-c$ plane with the yellow spheres indicating the intercalant sites while (b) shows the $\alpha$ and $\delta$ polymorphs on the $a-b$ plane. As indicated by the dashed blue regions, both the polymorphs differ by a change in the stacking of the $\mathrm{V}_{2} \mathrm{O}_{5}$ layers. 
the $b$-axis (i.e. in the $a-c$ plane), the orthorhombic $\mathrm{V}_{2} \mathrm{O}_{5}$ structure consists of layers of alternating corner- and edgesharing $\mathrm{VO}_{5}$ pyramids (shown in red), each consisting of $4 \mathrm{~V}-\mathrm{O}$ bonds that form the base and one short $\mathrm{V}=\mathrm{O}$ bond that forms the apex. The intercalation sites (yellow spheres) are situated in between the layers, and assuming no limitation in the number of redox centers, the theoretical gravimetric capacities for $\mathrm{AV}_{2} \mathrm{O}_{5}$ where $\mathrm{A}=\mathrm{Li}, \mathrm{Mg}, \mathrm{Zn}, \mathrm{Ca}$ and $\mathrm{Al}$ are 142, 260, 217, 242 and $385 \mathrm{mAh} \mathrm{g}^{-1}$, respectively. Structurally, the main difference between the $\alpha$ and $\delta$ polymorphs is a shift in the layer stacking, indicated by the dashed blue lines in Fig. $1 \mathrm{~b}$, with alternate $\mathrm{V}_{2} \mathrm{O}_{5}$ layers displaced in the $a$-direction by half a lattice spacing, accompanied by a change in the interlayer distance and the anion coordination environment of the intercalation sites. ${ }^{16}$ While 8 oxygen atoms coordinate the intercalant ion in $\alpha$ (for $\mathrm{Mg}$, there are two $\mathrm{Mg}-\mathrm{O}$ bonds with length $\sim 2.11 \AA$, two with $\sim 2.39 \AA$, and four with $\sim 2.46 \AA$, respectively), " $4+2$ " oxygen atoms coordinate the intercalant in $\delta$ (for $\mathrm{Mg}$, there are four $\mathrm{Mg}-\mathrm{O}$ bonds with length $\sim 2.05-2.07 \AA$, and two with $\sim 2.33 \AA$ ).

In Fig. 2a, the interlayer spacings in the $\alpha$ and $\delta$ polymorphs (filled and hollow bars, respectively) are shown for empty $\mathrm{V}_{2} \mathrm{O}_{5}$ and intercalated $\mathrm{AV}_{2} \mathrm{O}_{5}$, where $\mathrm{A}=\mathrm{Li}, \mathrm{Mg}, \mathrm{Zn}, \mathrm{Ca}$, and $\mathrm{Al}$. To better capture the increased effect of van der Waals effects in the deintercalated limit, the interlayer spacings for empty $\mathrm{V}_{2} \mathrm{O}_{5}$ (4.46 $\AA$ for $\alpha$; $5.03 \AA$ for $\delta$ ) are calculated using the vdW-DF2 functional ${ }^{20,21}$ rather than standard DFT as the latter significantly overestimates this spacing $(4.75 \AA$ for $\alpha ; 5.27 \AA$ for $\delta)$ compared to experiment $(4.37 \AA$ for $\alpha) \cdot{ }^{12,15,18}$ As detailed in the $\mathrm{ESI}, \dagger \mathrm{Al}^{3+}$ intercalation in the $\alpha-\mathrm{V}_{2} \mathrm{O}_{5}$ structure is found to be mechanically unstable and relaxes to the $\delta$ polymorph in our calculations, and we therefore remove it from further consideration in this study.

At the same intercalant composition, the $\delta$ structures consistently have larger layer spacings than $\alpha, \sim 3-5 \%$ larger for $\mathrm{Li}$, $\mathrm{Mg}$, and $\mathrm{Zn}$ and $\sim 10-12 \%$ for Ca and empty $\mathrm{V}_{2} \mathrm{O}_{5}$. With the exception of $\mathrm{Ca}$ intercalation, which increases the layer spacing by more than $10 \%$ in both polymorphs, the change in the layer spacing is much smaller in $\delta$ than $\alpha$, less than $2 \%$ for $\mathrm{Li}^{+}, \mathrm{Mg}^{2+}$, $\mathrm{Zn}^{2+}$, and $\mathrm{Al}^{3+}$ intercalation in $\delta-\mathrm{V}_{2} \mathrm{O}_{5}$ compared to $\sim 9-14 \%$ for $\mathrm{Li}^{+}, \mathrm{Mg}^{2+}, \mathrm{Zn}^{2+}$, and $\mathrm{Ca}^{2+}$ in $\alpha-\mathrm{V}_{2} \mathrm{O}_{5}$. The behavior for $\mathrm{Ca}^{2+}$ is consistent with intercalation in the spinel system, ${ }^{22}$ where the volume change is also much larger than for $\mathrm{Li}^{+}, \mathrm{Mg}^{2+}, \mathrm{Zn}^{2+}$, and $\mathrm{Al}^{3+}$ intercalation, and in general may be attributed to the larger ionic radius of $\mathrm{Ca}^{2+}$ in comparison to the other ions. ${ }^{23} \mathrm{Al}^{3+}$ intercalation in $\delta-\mathrm{V}_{2} \mathrm{O}_{5}$, in contrast to the other ions considered, is accompanied by a contraction of the layers, which is consistent with its small ionic radius and higher positive charge density that strengthens the attraction with nearby oxygen ions.

The average voltages of the compounds computed using the method of Aydinol et $a .^{24}$ are plotted in Fig. $2 \mathrm{~b}$ and are referenced to the potential of the bulk metal of the corresponding intercalating ion (i.e., Li metal for $\mathrm{Li}^{+}$intercalation, etc.). The average voltages computed for $\mathrm{Li}, \mathrm{Mg}$, and $\mathrm{Ca}$ intercalation compare very well to available experimental data: $\sim 3.2-3.4 \mathrm{~V}$ for Li measured by Delmas et al., ${ }^{16} \sim 2.2-2.4 \mathrm{~V}$ for $\mathrm{Mg}$ measured by Gershinsky et al., ${ }^{5}$ and $\sim 2.4-3.1 \mathrm{~V}$ for Ca measured by
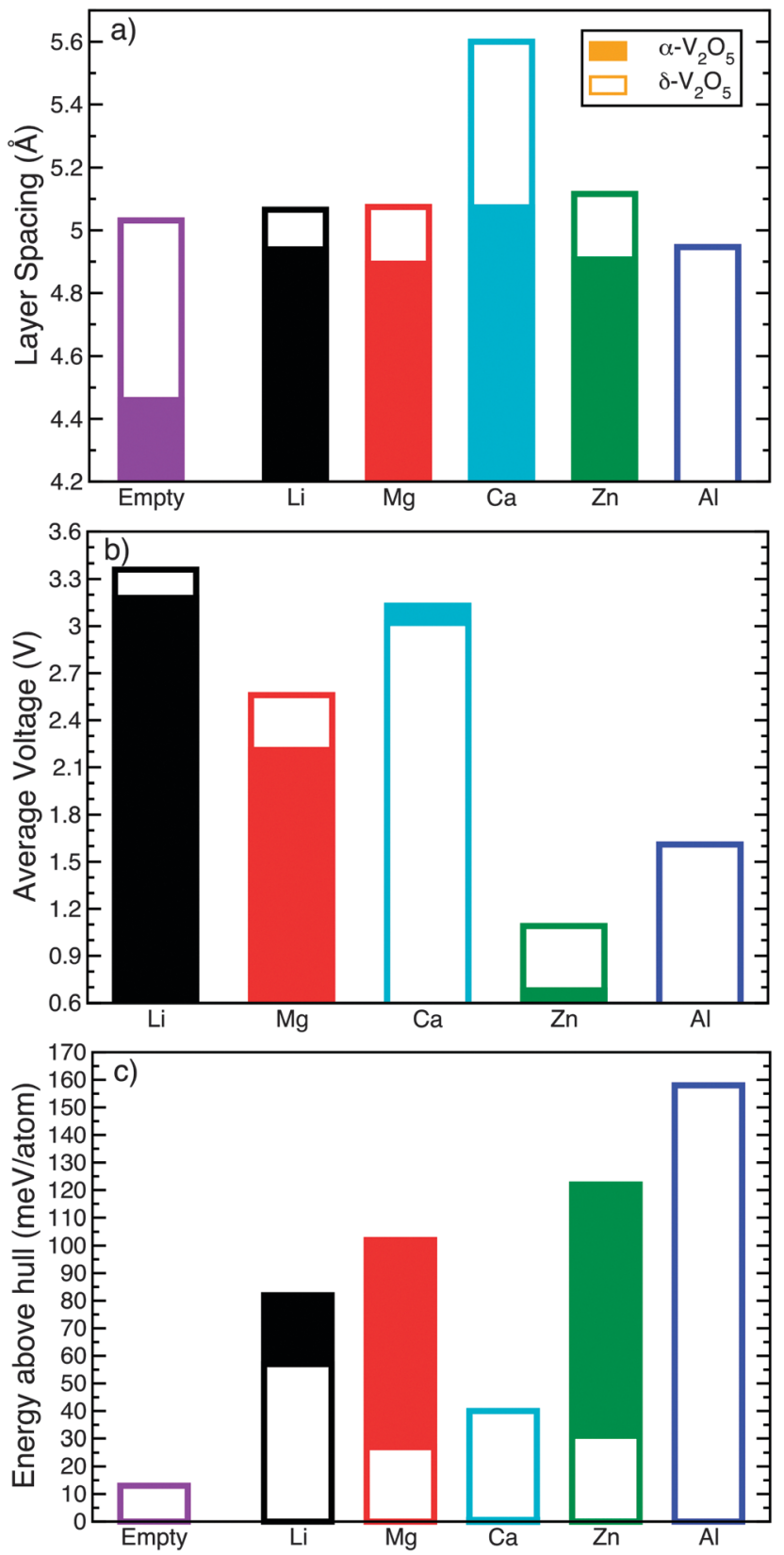

Fig. 2 (a) Plots the layer spacing values for the empty and intercalated versions of $\mathrm{AV}_{2} \mathrm{O}_{5}(\mathrm{~A}=\mathrm{Li}, \mathrm{Mg}, \mathrm{Ca}, \mathrm{Zn}$ and $\mathrm{Al})$ for both the $\alpha$ and $\delta$ polymorphs. (b) Displays the calculated average voltage values for the intercalation of the different ions and (c) shows the energy above hull, which quantifies the stability of a structure, for the empty and intercalated versions of $\alpha$ and $\delta$. The filled regions in all the graphs correspond to the $\alpha$ structure while the hollow regions correspond to the $\delta$ structure. Note that the energy above hull for $\alpha-\mathrm{CaV}_{2} \mathrm{O}_{5}$ is 0 meV per atom, implying that it is a ground state configuration in the $\mathrm{Ca}-\mathrm{V}-\mathrm{O}$ system.

Amatucci et al. ${ }^{6}$ In general, the Li polymorphs have the highest voltage, followed by $\mathrm{Ca}, \mathrm{Mg}, \mathrm{Al}$, and $\mathrm{Zn}$, which reflects both the same order and approximately the same potential difference indicated by the electrochemical series $(-3.04 \mathrm{~V} v$ s. SHE for $\mathrm{Li}$, $-2.86 \mathrm{~V}$ for $\mathrm{Ca},-2.37 \mathrm{~V}$ for $\mathrm{Mg},-1.66 \mathrm{~V}$ for $\mathrm{Al}$, and $-0.76 \mathrm{~V}$ for $\mathrm{Zn}$ ). In comparison, the voltage difference between the $\mathrm{V}_{2} \mathrm{O}_{5}$ polymorphs is much smaller for a given intercalation chemistry. 
For $\mathrm{Li}, \mathrm{Mg}$, and $\mathrm{Zn}$ the insertion voltage is higher in $\delta(3.36 \mathrm{~V}$, $2.56 \mathrm{~V}$, and $1.09 \mathrm{~V}$, respectively) than in $\alpha(3.18 \mathrm{~V}, 2.21 \mathrm{~V}$, and $0.68 \mathrm{~V}$ ), unlike for Ca where $\alpha$ is higher (3.13 V for $\alpha ; 3.02 \mathrm{~V}$ for $\delta$ ).

Fig. 2c displays the energy above the convex ground state energy hull ( $E^{\text {hull }}$ ) of the deintercalated and intercalated $\mathrm{V}_{2} \mathrm{O}_{5}$ polymorphs with respect to the intercalant-V-O ternary phase diagram. The ternary ground state hulls were determined from the available calculated compounds in the Materials Project database. ${ }^{25}$ A predicted thermodynamically stable structure will have a $E^{\text {hull }}$ value of $0 \mathrm{meV}$ per atom while higher (more positive) $E^{\text {hull }}$ values indicate greater instability, which may be reflected in experimental difficulties in synthesis or decomposition during battery operation. Note that the $E^{\text {hull }}$ values calculated here reflect the ground state (i.e. $0 \mathrm{~K}$ ), and entropy contributions, which scale with $k_{\mathrm{B}} T$, can stabilize certain structures at higher temperatures.

In the deintercalated limit, $\mathrm{V}_{2} \mathrm{O}_{5}$ is thermodynamically stable in the $\alpha$ phase, but $\delta$ is only $\sim 13 \mathrm{meV}$ per atom higher in energy, indicating the possibility of metastability at room temperature. For Li intercalation, the $\alpha$ and $\delta$ structures are $82 \mathrm{meV}$ per atom and $57 \mathrm{meV}$ per atom more unstable than the ground state orthorhombic $\gamma-\mathrm{LiV}_{2} \mathrm{O}_{5}$ structure, which has a different orientation of the $\mathrm{VO}_{5}$ pyramids ${ }^{16}$ along the $c$-direction shown in Fig. 1a, but the $\delta$ structure can remain metastable and has shown to be reversibly cycled electrochemically. ${ }^{16} \delta-\mathrm{MgV}_{2} \mathrm{O}_{5}$, which has been synthesized experimentally, ${ }^{17}$ is only $\sim 27 \mathrm{meV}$ per atom more unstable (compared to $\sim 102 \mathrm{meV}$ per atom for $\alpha$ ) than the thermodynamic ground state, a two-phase equilibrium consisting of $\mathrm{MgVO}_{3}$ and $\mathrm{VO}_{2}$. Similarly $\delta-\mathrm{ZnV}_{2} \mathrm{O}_{5}$ is only $\sim 31 \mathrm{meV}$ per atom more unstable than the ground state $\left(\mathrm{ZnO}\right.$ and $\left.\mathrm{VO}_{2}\right)$, indicating that a metastable synthesis comparable to the $\mathrm{Mg}$ system may be possible. As $\mathrm{Al}$ intercalated $\alpha-\mathrm{V}_{2} \mathrm{O}_{5}$ displays mechanical instability in our calculations, when relaxed its energy is not defined, but the $\mathrm{Al}$ intercalated $\delta$-phase is $\sim 158 \mathrm{meV}$ per atom unstable compared to the ground state ternary equilibrium of $\mathrm{Al}_{2} \mathrm{O}_{3}, \mathrm{VO}_{2}$ and $\mathrm{V}_{3} \mathrm{O}_{5}$. With the exception of $\alpha-\mathrm{CaV}_{2} \mathrm{O}_{5}$, which is the ground state in the intercalated $\mathrm{Ca}-\mathrm{V}_{2} \mathrm{O}_{5}$ system, the $\delta$ structures tend to be more stable than $\alpha$ in the discharged state (by $25 \mathrm{meV}$ per atom for $\mathrm{Li}$; $75 \mathrm{meV}$ per atom for $\mathrm{Mg}$; and $91 \mathrm{meV}$ per atom for $\mathrm{Zn}$ ), and accordingly the insertion voltages for $\delta$ are higher than $\alpha$ for $\mathrm{Li}, \mathrm{Mg}$, and $\mathrm{Zn}$ insertion but lower for $\mathrm{Ca}$ insertion, as observed in Fig. 2b. Given that the intercalant sites in $\alpha$ and $\delta$ are coordinated by 8 and " $4+2$ " oxygen atoms respectively, the stability of the discharged $\delta-\mathrm{V}_{2} \mathrm{O}_{5}$ structures for $\mathrm{Li}, \mathrm{Mg}$ and $\mathrm{Zn}$, and $\alpha-\mathrm{V}_{2} \mathrm{O}_{5}$ for $\mathrm{Ca}$ align well with the preferred coordination environment of the respective ions, as tabulated by Brown. ${ }^{26}$ Hence for intercalant ions that prefer a lower coordination number (i.e., coordinated by a maximum of 6 neighboring atoms), an $\alpha \rightarrow \delta$ transition upon insertion in $\mathrm{V}_{2} \mathrm{O}_{5}$ is likely.

Fig. 3 displays the migration energies for intercalant diffusion along the $a$-direction in the $\alpha$ (Fig. 3a) and $\delta$ (Fig. 3b) polymorphs plotted against the normalized path distance calculated with the Nudged Elastic Band method. ${ }^{27}$ The solid lines correspond to migration energies obtained in the empty lattice limit (charged state), and the dashed lines correspond to the fully intercalated limit (discharged state). As elaborated upon in the ESI, $\dagger$

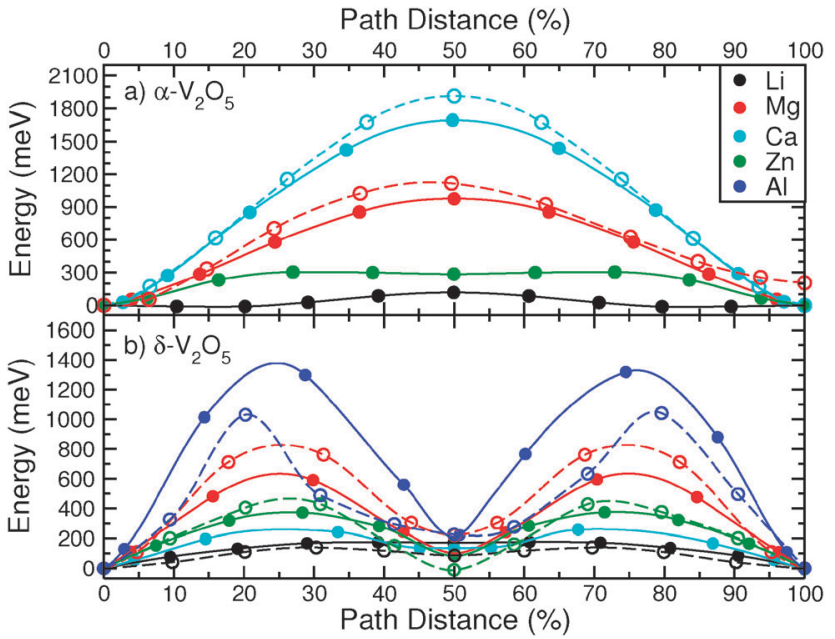

Fig. 3 The activation barriers for the diffusion of the different intercalating ions in the $\alpha$ and $\delta$ polymorphs are plotted in (a) and (b) respectively. The solid lines correspond to the empty lattice limit (charged state) while the hollow lines correspond to the full lattice limit (discharged state).

converging the migration energies in structures that exhibit a high degree of thermodynamic instability may not be possible, as was the case for $\mathrm{Li}, \mathrm{Mg}$, and $\mathrm{Zn}$ in the intercalated $\alpha-\mathrm{V}_{2} \mathrm{O}_{5}$ structure, and for $\mathrm{Ca}$ in the intercalated $\delta-\mathrm{V}_{2} \mathrm{O}_{5}$ structure. In lieu of determining the $\mathrm{Mg}$ migration barrier in the fully discharged $\alpha-\mathrm{V}_{2} \mathrm{O}_{5}$ structure, we have computed the energy for $\mathrm{Mg}$ migration in a half intercalated structure with a specific ordering of $\mathrm{Mg}$ ions, referred to as the " $\varepsilon$ " phase, which has also been observed in the $\mathrm{Li}-\mathrm{V}_{2} \mathrm{O}_{5}$ system. ${ }^{16}$

In Fig. 3, the maximum energy difference encountered along the diffusion path defines the migration barrier $\left(E_{\mathrm{m}}\right)$, which provides an approximate estimate of the ionic diffusivity. As a guide, at room temperature, $E_{\mathrm{m}} \sim 525 \mathrm{meV}$ corresponds to a diffusivity of $\sim 10^{-12} \mathrm{~cm}^{2} \mathrm{~s}^{-1}$, and a $60 \mathrm{meV}$ increase (decrease) in the migration energy corresponds to an order of magnitude decrease (increase) in diffusivity. Due to stronger interactions between a multivalent intercalant and the surrounding anion environment, the migration barriers within the same host structure, for example $\mathrm{Al}^{3+}$, are generally higher than the divalent ion barriers $\left(\mathrm{Mg}^{2+}, \mathrm{Zn}^{2+}, \mathrm{Ca}^{2+}\right)$, which are generally higher than the barriers for $\mathrm{Li}^{+}$. For the divalent intercalants, the trend in the migration barriers is $\mathrm{Ca}^{2+}(\sim 1700-1900 \mathrm{meV})>\mathrm{Mg}^{2+}$ $(\sim 975-1100 \mathrm{meV})>\mathrm{Zn}^{2+}(\sim 305 \mathrm{meV})$ in the $\alpha$-phase, but $\mathrm{Mg}^{2+}$ $(\sim 600-800 \mathrm{meV})>\mathrm{Zn}^{2+}(\sim 375-425 \mathrm{meV})>\mathrm{Ca}^{2+}(\sim 200 \mathrm{meV})$ in the $\delta$ phase. The energy above the hull (Fig. 2c) ranked from the lowest to highest reflects this same trend, with $\mathrm{Ca}^{2+}>\mathrm{Mg}^{2+}>\mathrm{Zn}^{2+}$ in $\alpha$ and $\mathrm{Mg}^{2+}>\mathrm{Zn}^{2+}>\mathrm{Ca}^{2+}$ for $\delta$, and highlights the positive correlation between high intercalant mobility and low thermodynamic stability. For both $\mathrm{V}_{2} \mathrm{O}_{5}$ polymorphs considered, the change in the migration barrier from the deintercalated to intercalated limit for the same diffusing species is much smaller than the variation across intercalating ions.

Although the $\alpha$ and $\delta$ polymorphs of $\mathrm{V}_{2} \mathrm{O}_{5}$ are structurally very similar as earlier discussed, the anion coordination environment and therefore diffusion topology of the migrating intercalant 
vary significantly, which accounts for the different shape of the migration energies seen in Fig. $3 a$ and $b$. In the $\alpha$ phase, the stable insertion site is coordinated by 8 oxygen anions which is connected to the adjacent insertion site along the $a$-axis by a 3-coordinated shared face. The shape of the migration energies shown in Fig. 3a, therefore, reflect the change in coordination of $8 \rightarrow 3 \rightarrow 8$ encountered by the diffusing species with the migration barrier corresponding to passing through the shared face. For the $\delta$ phase, the stable insertion site adopts a " $4+2$ ", coordination and shares a corner with the adjacent insertion site along the $a$-axis. To migrate to this site, the intercalant passes through a 3-coordinated face shared with an intermediate 5-coordinated (pyramidal) site, and finally performs a symmetric hop to the next insertion site. The change in the anion coordination along the diffusion path is then " $4+2$ " $\rightarrow$ $3 \rightarrow 5 \rightarrow 3 \rightarrow$ " $4+2$ ", where occupation of the intermediate pyramidal site corresponds to a local minimum in the migration energy, as is reflected in Fig. 3b. Overall, the migration barriers are also lower in the $\delta$ phase compared to $\alpha$ (significantly lower for some cases), which we attribute in large part to the smaller coordination change during the migration process encountered in $\delta$. Also, the change in the relative order of the migration barriers of divalent ions between $\alpha(\mathrm{Ca}>\mathrm{Mg}, \mathrm{Zn})$ and $\delta(\mathrm{Mg}, \mathrm{Zn}>\mathrm{Ca})$ can be explained by the correlation between the "preferred" coordination environments of the respective ions and the available anion coordination environments around the intercalation sites. ${ }^{28}$ In a given structure, migration barriers are higher for an ion whose preferred coordination aligns with that of the coordination environment available for the intercalant site compared to an ion whose preferred coordination is different from that present in the structure. For example, $\mathrm{Ca}$ is in its preferred 8-coordinated site in $\alpha$ and hence has higher barriers than $\mathrm{Mg}$ and $\mathrm{Zn}$, which are not in their respectively preferred 6 and 4 coordinated sites. Whereas in $\delta$, Ca is present in an unfavored " $4+2$ " coordinated site and hence has lower barriers than either of $\mathrm{Mg}$ or $\mathrm{Zn}$, which are closer to their preferred coordination environments. Our results thus lend support to the hypothesis that coordination of the intercalation site is a good screening criterion for identifying fast multivalent cation diffusers.

An ideal MV cathode intercalation host must possess several properties - high capacity, high insertion voltage, and MV ion mobility, while simultaneously minimal structural change and thermodynamic instability. From the systematic first-principles study performed in this work, we are able to evaluate all of the candidate materials across each of these criteria. On the basis of ion mobility, $\mathrm{Al}^{3+}$ intercalation appears unfeasible at room temperature in $\mathrm{V}_{2} \mathrm{O}_{5}$ due to its prohibitively high migration barriers, and although $\mathrm{Zn}^{2+}$ intercalation is determined to be facile in both polymorphs and relatively stable in the $\delta$ phase, the insertion voltage is low. Mobility of $\mathrm{Mg}^{2+}$ and $\mathrm{Ca}^{2+}$ is determined to be poor in the $\alpha$ phase, but intercalation of these ions in the $\delta$ phase appear most promising, with sufficiently high voltage (3.02 V for $\mathrm{Ca}$, and $2.56 \mathrm{~V}$ for $\mathrm{Mg}$ ) and mobility $\left(E_{\mathrm{m}} \sim 200 \mathrm{meV}\right.$ for $\mathrm{Ca}$ and $\sim 600-800 \mathrm{meV}$ for $\mathrm{Mg}$ ) albeit with moderate thermodynamic instability $(27 \mathrm{meV}$ per atom for $\mathrm{Mg}$ and $40 \mathrm{meV}$ per atom for $\mathrm{Ca}$ above the ground state hull in the discharged state).

The current work is fully supported by the Joint Center for Energy Storage Research (JCESR), an Energy Innovation Hub funded by the U.S. Department of Energy, Office of Science and Basic Energy Sciences. This study is supported by Subcontract 3F-31144. The authors would like to thank the National Energy Research Scientific Computing Center (NERSC) for providing computing resources.

\section{References}

1 R. V. Noorden, Nature, 2014, 507, 26-28.

2 D. Aurbach, Z. Lu, A. Schechter, Y. Gofer, H. Gizbar, R. Turgeman, Y. Cohen, M. Moshkovich and E. Levi, Nature, 2000, 407, 724-727.

3 I. Shterenberg, M. Salama, Y. Gofer, E. Levi and D. Aurbach, MRS Bull., 2014, 39, 453-460.

4 H. D. Yoo, I. Shterenberg, Y. Gofer, G. Gershinsky, N. Pour and D. Aurbach, Energy Environ. Sci., 2013, 6, 2265.

5 G. Gershinsky, H. D. Yoo, Y. Gofer and D. Aurbach, Langmuir, 2013, 29, 10964-10972.

6 G. G. Amatucci, F. Badway, A. Singhal, B. Beaudoin, G. Skandan, T. Bowmer, I. Plitz, N. Pereira, T. Chapman and R. Jaworski, J. Electrochem. Soc., 2001, 148, A940.

7 J. Muldoon, C. B. Bucur, A. G. Oliver, T. Sugimoto, M. Matsui, H. S. Kim, G. D. Allred, J. Zajicek and Y. Kotani, Energy Environ. Sci., 2012, 5, 5941.

8 K. Kang and G. Ceder, Phys. Rev. B: Condens. Matter Mater. Phys., 2006, 74, 094105.

9 A. Van Der Ven, J. Bhattacharya and A. A. Belak, Acc. Chem. Res., 2013, 46, 1216-1225.

10 Y. S. Meng and M. E. Arroyo-De Dompablo, Acc. Chem. Res., 2013, 46, 1171-1180.

11 G. Yoon, D.-H. Seo, K. Ku, J. Kim, S. Jeon and K. Kang, Chem. Mater., 2015, 27, 2067-2073.

12 G. Sai Gautam, P. Canepa, A. Abdellahi, A. Urban, R. Malik and G. Ceder, Chem. Mater., 2015, 27, 3733-3742.

13 Z. Wang, Q. Su and H. Deng, Phys. Chem. Chem. Phys., 2013, 15, 8705-8709.

14 B. Zhou, H. Shi, R. Cao, X. Zhang and Z. Jiang, Phys. Chem. Chem. Phys., 2014, 16, 18578-18585.

15 J. Carrasco, J. Phys. Chem. C, 2014, 118, 19599-19607.

16 C. Delmas, H. Cognac-Auradou, J. M. Cocciantelli, M. Ménétrier and J. P. Doumerc, Solid State Ionics, 1994, 69, 257-264.

17 P. Millet, C. Satto, P. Sciau and J. Galy, J. Solid State Chem., 1998, 62, 56-62.

18 R. Enjalbert and J. Galy, Acta Crystallogr., Sect. C: Cryst. Struct. Commun., 1986, 42, 1467-1469.

19 H. G. Bachmann, F. R. Ahmed and W. H. Barnes, Z. Kristallogr. - Cryst. Mater., 1961, 115, 110-131.

20 K. Lee, E. D. Murray, L. Kong, B. I. Lundqvist and D. C. Langreth, Phys. Rev. B: Condens. Matter Mater. Phys., 2010, 82, 081101(R).

21 J. Klime, D. R. Bowler and A. Michaelides, Phys. Rev. B: Condens. Matter Mater. Phys., 2011, 83, 195131.

22 M. Liu, Z. Rong, R. Malik, P. Canepa, A. Jain, G. Ceder and K. A. Persson, Energy Environ. Sci., 2015, 8, 964-974.

23 R. D. Shannon and C. T. Prewitt, Acta Crystallogr., Sect. B: Struct. Crystallogr. Cryst. Chem., 1969, 25, 925-946.

24 M. Aydinol, A. Kohan and G. Ceder, J. Power Sources, 1997, 68, 664-668.

25 A. Jain, S. P. Ong, G. Hautier, W. Chen, W. D. Richards, S. Dacek, S. Cholia, D. Gunter, D. Skinner, G. Ceder and K. A. Persson, APL Mater., 2013, 1, 011002.

26 I. D. Brown, Acta Crystallogr., Sect. B: Struct. Sci., 1988, 44, 545-553. 27 D. Sheppard, R. Terrell and G. Henkelman, J. Chem. Phys., 2008, 128, 134106.

28 Z. Rong, R. Malik, P. Canepa, G. Sai Gautam, M. Liu, A. Jain, K. A. Persson and G. Ceder, 2015, submitted. 